\title{
Assessing climate change effects on gladiola in Southern Brazil
}

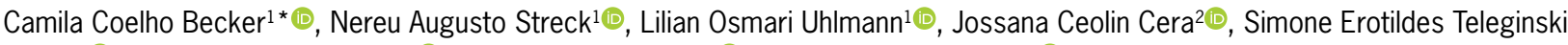

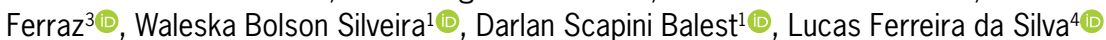

\author{
1Universidade Federal de Santa Maria/CCR - Depto. de \\ Fitotecnia, Av. Roraima, 1000 - 97105-900 - Santa Maria, \\ RS - Brasil. \\ 2Instituto Rio Grandense do Arroz, Av. Missões, 342 - \\ 90230-100 - Porto Alegre, RS - Brasil. \\ 3Universidade Federal de Santa Maria/CCNE - Depto. de \\ Física, Av. Roraima, 1000 - 97105-900 - Santa Maria, RS \\ - Brasil. \\ ${ }^{4}$ Universidade Federal de Santa Maria/CT - Depto. de \\ Linguagens e Sistemas de Computação, Av. Roraima, 1000 \\ - 97105-900 - Santa Maria, RS - Brasil. \\ *Corresponding author <camilabecker07@hotmail.com>
}

Edited by: Gerrit Hoogenboom

Received August 17, 2018

Accepted July 30, 2019
ABSTRACT: Gladiola (Gladiolus $\times$ grandiflorus Hort.) is an important cut flower for small farmers in Brazil. While the EI Niño Southern Oscillation, which causes interannual variability to air temperature in Southern Brazil, can shift the optimum planting window of gladiola, an increase in temperature due to climate change can accelerate gladiola flowering and cause injuries by heat. The objective of this study was to assess the potential climate change effects on gladiola optimum planting date for specific market dates and investigate injuries occurrence on spikes in the Rio Grande do Sul State, Brazil. Field experiments were conducted from 2016 to 2018 at four different locations across the Rio Grande do Sul State to evaluate the performance of the PhenoGlad model in simulating the developmental stages of gladiola. The PhenoGlad model was run on climate scenarios of the Coupled Model Intercomparison Project Phase 5 (CMIP5) named RCP2.6, RCP4.5 and RCP8.5 scenarios. The climate change scenarios caused a delay in the optimum planting date to harvest gladiola for All Souls' Day across the Rio Grande do Sul State. For harvesting spikes for Mother's Day, negative anomalies (earliest planting date) occurred in the warmest regions, because the very high temperature extended the crop development. Injuries by heat on spikes reached positive anomalies in $70 \%$ of the years in the warmest regions for scenario RCP8.5. To harvest spikes for Mother's Day, heat injury did not exceed $20 \%$ of the years. Mitigation strategies for farmers to deal with climate change and keep their gladiola production include adjusting the optimum planting date.

Keywords: rising temperature, heat injuries, spike quality, planting date

\section{Introduction}

The increase of greenhouse gases (GHG) emissions into the atmosphere is a major cause of the increase of global surface temperature. The latest report of the Intergovernmental Panel on Climate Change (IPCC) indicates an average global temperature increase of $0.85^{\circ} \mathrm{C}$ from 1880 to 2012 , with the largest increase in the 1990's (Kerr, 2005; IPCC, 2013). In the subtropics of Southern Brazil, which includes the state of Rio Grande do Sul, daily thermal amplitude in summer months decreased from 1960 to 2002 because of a larger increase in minimum temperature (Marengo and Camargo, 2008).

Agriculture is highly vulnerable to climate change (Alexandrov and Hoogenboom, 2000; IPCC, 2013) and several studies have shown an impact on crops yield mainly at the end of last century (Hur and Ahn, 2015; Ramirez-Villegas and Thornton, 2015; Bhattarai et al., 2017; Cera et al., 2017). For ornamental crops grown in open field, temperature changes may cause major losses because the market requires that flowering occur within a rather narrow time window to meet the market demand (Snipen et al., 1999; Fisher and Lieth, 2000; Munir et al., 2015). In Rio Grande do Sul State, the cultivated area with floriculture crops covers 1,360 ha and the sector generates about 11,000 jobs (Ibraflor, 2018). However, roughly $90 \%$ of the cut flowers consumed come from other states and gladiola is an alternative crop to supply this demand.

Gladiola is one of the most popular bulbous cut flowers worldwide (Thakur et al., 2015) and an important crop for small farmers in Brazil because it is easily grown in open field. Air temperature is the main abiotic factor that drives gladiola phenology (Schwab et al., 2015). Climate variability such as the El Niño Southern Oscillation (ENSO), which causes interannual variability to air temperature in Southern Brazil, can shift the optimum planting window of gladiola according to the ENSO phase (Becker et al., 2020). While studying the ENSO effect produces short-term responses to gladiola farmers, studies on climate change are important for the long term and may drive decisions of policy makers, management practices, and breeding programs. Therefore, a practical and important question for farmers is how climate change, mainly global warming, can affect gladiola phenology and flower quality compared to the current climate? Furthermore, if phenology is affected, how optimum planting date needs to be shifted to reach market targets? The objective of this study was to assess the potential climate change effects on optimum planting date of gladiola to meet de demands of specific market dates as well as investigate injuries occurrence on spikes in the Rio Grande do Sul State, Brazil.

\section{Materials and Methods}

\section{The study region and climate scenarios}

This study was performed in the State of Rio Grande do Sul, Southern Brazil, (Figure 1A). According to Köppen climate classification system, the state has regions with humid subtropical climate without dry seasons and hot summers (Cfa) and regions with temperate summers (Cfb) (Alvares et al., 2013). 
The scenarios of climate change used in this study were obtained from the Assessment Report Five (AR5) of the IPCC, derived from the Coupled Model Intercomparison Project Phase 5 (CMIP5). Three scenarios were used: RCP2.6, RCP4.5, and RCP8.5 (RCP stands for Representative Concentration Pathwayl, representing optimistic, intermediate and pessimistic scenarios of GHG emissions, respectively. Climate scenarios were generated with the global oceanatmosphere HadGEM-ES model (Jones et al., 2011) with a $250-\mathrm{km}$ spatial resolution and used as boundary conditions for downscaling to a regional basis with a 81-km resolution with the RegCM4 (Regional Climate Model, version 4), totaling 46 grid points across Rio Grande do Sul State (Figure 1B). The projections of temperature increase and $\mathrm{CO}_{2}$ concentration until 2100 are $1.7^{\circ} \mathrm{C}$ and $421 \mathrm{ppm}$ for RCP2.6 scenario, $2.6^{\circ} \mathrm{C}$ and $538 \mathrm{ppm}$ for RCP4.5 scenario, and $4.8^{\circ} \mathrm{C}$ and $936 \mathrm{ppm}$ for RCP8.5 scenario (IPCC, 2013). Two periods were used for each grid points: 1976 to 2005 (baseline period) and 2070 to 2098 (for each climatic scenarios).

\section{The PhenoGlad model}

The model used in this study was PhenoGlad (Uhlmann et al., 2017), a dynamic process-based gladiola phenology model that was previously calibrated and validated with different cultivars, planting dates, years, and locations from experiments conducted in two southern states in Brazil, Rio Grande do Sul State and Santa Catarina (Uhlmann et al., 2017). In PhenoGlad, gladiola phenology is simulated without water limitations and considering three main phases based on the developmental scale by Schwab et al. (2015): sprouting phase, vegetative phase, and reproductive phase. Starting at planting, the developmental stage (DVS) is calculated by accumulating the daily developmental rate values, using daily mean air temperature, using the nonlinear approach of Wang and Engel (1998). A nonlinear temperature response function is used to penalize crop development when daily air temperature is below or above the optimum temperature. The PhenoGlad model simulates the development of selected cultivars or, in the general mode, of four different maturity group (MG): Early, Intermediate I, Intermediate II and Late. Each MG has a maximum daily developmental rate that represents a group of cultivars belonging to this MG. The cardinal temperatures: minimum (Tb), optimum (Topt) and maximum (TB) in the sprouting phase are $\mathrm{Tb}=5^{\circ} \mathrm{C}$, Topt $=25^{\circ} \mathrm{C}$, and $\mathrm{TB}=35^{\circ} \mathrm{C}$. In the vegetative phase, the cardinal temperatures are $\mathrm{Tb}=2{ }^{\circ} \mathrm{C}$, Topt $=27^{\circ} \mathrm{C}$ and $\mathrm{TB}=45^{\circ} \mathrm{C}$ and in the reproductive phase, cardinal temperatures are $\mathrm{Tb}=6{ }^{\circ} \mathrm{C}$, Topt $=25^{\circ} \mathrm{C}$ and $\mathrm{TB}=$ $42{ }^{\circ} \mathrm{C}$. Input data required to run the PhenoGlad include daily minimum and maximum air temperatures, planting or emergence date and cultivar or MG (Early, Intermediate I, Intermediate II and Late). Air temperature is the only factor that controls gladiola development in PhenoGlad and the model was calibrated under potential condition (without water limitation) (Uhlmann et al., 2017). Most farmers in the state, even small farmers, use irrigation in their gladiola beds. In this study, we are looking at direct effects of climate change (air temperature) on gladiola plants. Version 1.1 of the PhenoGlad model, available at www.ufsm.br/phenoglad, was used in the study.

The PhenoGlad model also simulates the occurrence of crop injuries caused by low (freezing)

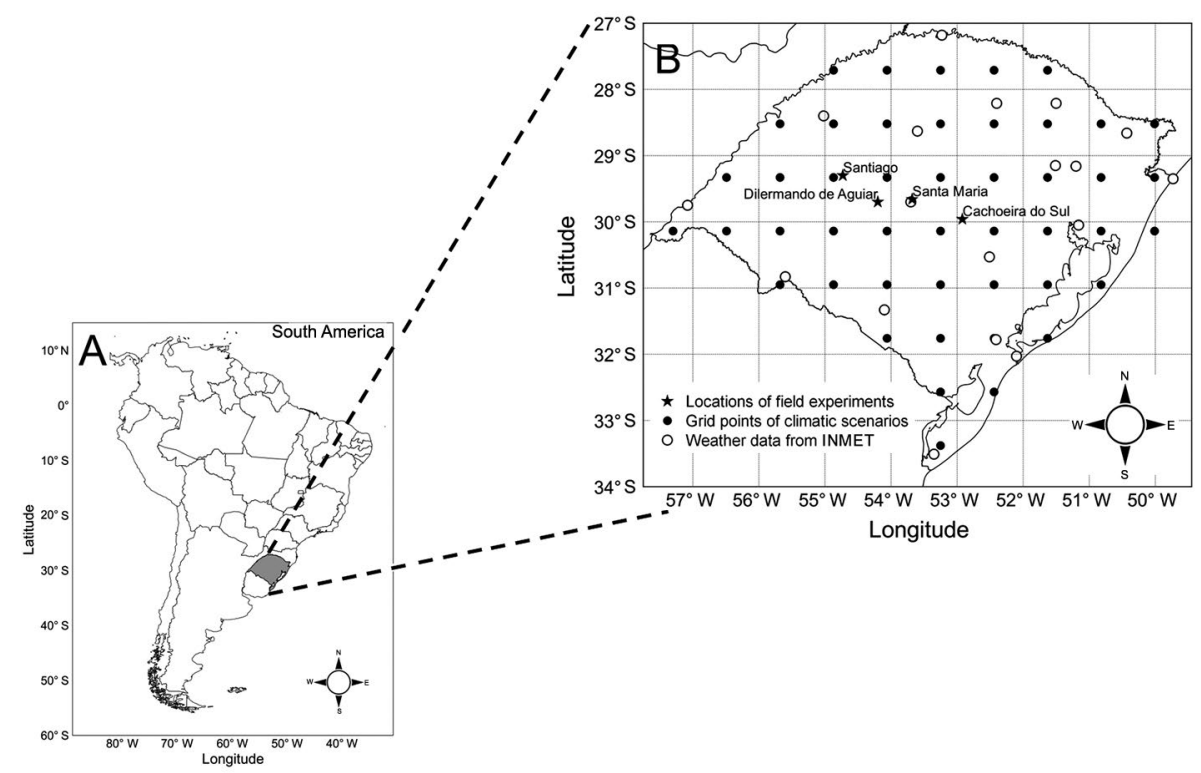

Figure 1 - Maps of South America and Brazil (A), and Rio Grande do Sul State (B) with the four locations (Santa Maria, Cachoeira do Sul, Dilermando de Aguiar, and Santiago) where field experiments with gladiola were conducted. The grid points of the climate scenarios and the 18 locations of weather stations from the Brazilian Meteorological Service (INMET) used in this study. 
and high (heat) temperatures. When daily minimum temperature (Tmin) is lower than $-2{ }^{\circ} \mathrm{C}$ during at least four days in a row from emergence to the R5 stage, then the crop is killed by frost. If minimum temperature is lower than or equal to $-2{ }^{\circ} \mathrm{C}$ for one day or if $-2{ }^{\circ} \mathrm{C}$ $<$ Tmin $<3{ }^{\circ} \mathrm{C}$ during 4 days in a row during the reproductive phase, then the spike is killed by frost. Heat injury in PhenoGlad is considered when maximum temperature is greater than or equal to $34^{\circ} \mathrm{C}$ during three consecutive days during the reproductive phase, causing severe burning on sepals. If the maximum temperature is higher than $48{ }^{\circ} \mathrm{C}$, the upper lethal temperature is reached and the crop is killed by heat.

In addition to the previous validation of PhenoGlad (Uhlmann et al., 2017), other independent field experiments were conducted from 2016 to 2018 at four different locations across Rio Grande do Sul State to evaluate the performance of the PhenoGlad model in simulating the developmental stages of gladiola (Figure 1B). The experiments were conducted in the municipality of Santa Maria, Rio Grande do Sul (latitude: 29 $43^{\prime} \mathrm{S}$, longitude: $53^{\circ} 43^{\prime} \mathrm{W}$ and altitude: $95 \mathrm{~m}$ ). Experiments were also conducted at commercial farms in Santa Maria (latitude: $29^{\circ} 39^{\prime} \mathrm{S}$, longitude: $53^{\circ} 40^{\prime} \mathrm{W}$ and altitude: $115 \mathrm{~m}$ ), Dilermando de Aguiar (latitude: $29^{\circ} 2^{\prime} \mathrm{S}$, longitude: $54^{\circ} 12^{\prime} \mathrm{W}$ and altitude: $133 \mathrm{~m}$ ), Cachoeira do Sul (latitude: $29^{\circ} 57^{\prime} \mathrm{S}$, longitude: $52^{\circ} 55^{\prime}$ W and altitude: $26 \mathrm{~m}$ ) and Santiago (latitude: $29^{\circ} 18^{\prime} \mathrm{S}$, longitude: $54^{\circ} 43^{\prime} \mathrm{W}$ and altitude: $409 \mathrm{~m}$ ), totaling five experiments with different cultivars, planting dates and locations (Table 1).

During all field experiments, the date of occurrence of vegetative and reproductive developmental stages were observed on tagged plants (20 plants per plot) according to the phenological scale of gladiola (Schwab et al., 2015). The date of developmental stages was considered when $50 \%$ of plants had reached the stages. The cumulative leaf number (CLN) was counted twice a week in Santa Maria, and in the other locations every other week, until the final leaf (flag leaf) was visible. The reproductive stages observed were heading (R1) and blooming (R2 stage, considered the harvest point for gladiola) (Schwab et al., 2015).

The model evaluation consisted of running the PhenoGlad model starting at planting date for each cultivar, location, and planting date. Daily data on the weather were obtained from automatic weather stations of the Brazilian National Weather Service (INMET) in Santa Maria and Santiago. Daily data on the weather from Santa Maria were used to run the model in the experiments at Dilermando de Aguiar and Cachoeira do Sul. The model performance was evaluated with the statistics Root Mean Square Error (RMSE), BIAS index (Wallach, 2006), index of agreement (dw) (Willmott, 1981), correlation coefficient (r), and systematic (MSEs) and unsystematic (MSEns) errors (Willmott, 1981). Low RMSE, zero BIAS, one dw and $r$, and low systematic and high unsystematic error are characteristics of a good model.

We compared the DAP (days after planting) until the R2 stage simulated using the baseline period and weather stations (WS) of the INMET to evaluate the ability of the PhenoGlad model to simulate the current optimum planting date for harvesting gladiola flowers for All Souls' Day and Mother's Day, with the baseline of the climate scenarios. PhenoGlad was run for 18 locations of the INMET WS in Rio Grande do Sul and for the nearest grid point of the baseline period (1976-2005) (Figure 1B). The statistics used to test the difference in the duration of developmental cycle of gladiola was the same as mentioned above.

\section{Simulations of the optimum planting date}

The optimum planting date was simulated for each market target day, grid point, maturation group, and each CMIP5 climate scenario by running the PhenoGlad model for four MG of gladiola (Early, Intermediate I, Intermediate II and Late), which vary

Table 1 - Experiments conducted in southern Brazil with locations, planting dates ( $\mathrm{mm} / \mathrm{dd} / \mathrm{yyyy}$ ) and Gladiola cultivars used to evaluate the PhenoGlad model.

\begin{tabular}{|c|c|c|c|}
\hline Experiment number & Location & Planting dates & Cultivars \\
\hline 1 & Santa Maria & $\begin{array}{c}12 / 02 / 2016,07 / 14 / 2017 \\
11 / 22 / 2017\end{array}$ & $\begin{array}{l}\text { Purple Flora and Peter Pears (only on 12/02/2016), Jester (not in 2016) } \\
\text { and Rose Friendship (not in 07/14/2017) }\end{array}$ \\
\hline \multirow{9}{*}{2} & \multirow{9}{*}{ On Farm, Santa Maria } & 07/21/2016 & Red Beauty, Peter Pears \\
\hline & & 08/04/2016 & Amsterdam \\
\hline & & 02/17/2017 & Gold Field, Jester \\
\hline & & 02/20/2017 & Red Beauty \\
\hline & & 02/24/2017 & Peter Pears, Rose Friendship, Amsterdam \\
\hline & & 07/17/2017 & Jester \\
\hline & & 07/27/2017 & Amsterdam, Peter Pears \\
\hline & & $02 / 16 / 2018$ & Fidelio, Red Beauty, Rose Supreme, Jester \\
\hline & & 02/19/2018 & Red Beauty, Rose Supreme, Jester \\
\hline 3 & On Farm, Dilermando de Aguiar & $02 / 14 / 2018$ & \multirow{3}{*}{$\begin{array}{l}\text { Red Beauty, Rose Supreme, Jester, White Goddess (not in Dilermando de } \\
\text { Aguiar), Fidelio (not in Dilermando de Aguiar) }\end{array}$} \\
\hline 4 & On Farm, Cachoeira do Sul & 02/15/2018 & \\
\hline 5 & On Farm, Santiago & 02/19/2018 & \\
\hline
\end{tabular}


in their developmental cycle from 69 to 121 days for early cultivars and from 85 to 148 days for late cultivars. For each year and each MG, the optimum planting date was simulated in order to have plants with the first three florets showing the characteristic color of the cultivar (the R2 stage of the phenological scale by Schwab et al., 2015) three days before Mother's Day (second Sunday of May) and All Souls' Day (November 2). The optimum planting date in the future period (2070-2098) was presented as anomalies calculated from the difference between the optimum planting dates in each year in the future period and average optimum planting date in the baseline period for each grid point and maturation group.

\section{Plant injuries}

For each optimum planting date, the occurrence of crop damage due to freezing or heat was assessed, and the percentage of years with damages for each grid point, MG, and climate scenarios was calculated. The percentage of years with damage was also presented as anomalies (anomalies here are the difference between the percentage of years with damage in the future period and the percentage of years with damage in the baseline). Maps were generated with the Quantum GIS software using the inverse distance weighted (IDW) interpolation approach for a better view of the spatial distribution of anomalies of optimum planting dates and percentage of years with damage for all climate scenarios,

\section{Results}

The cumulative leaf number (CLN) simulated by the PhenoGlad model were close to the observed data collected in the experiments and on the farms (Figure 2A), with an overall RMSE of 0.8 leaves. Decomposing the RMSE into systematic (MSEs) and non-sistematic
(MSEns) components, the MSEs was $42.3 \%$ and the MSEns was $57.7 \%$. The BIAS index was -0.10 and the $\mathrm{dw}$ and $\mathrm{r}$ were high, 0.98 and 0.97 , respectively. Simulated versus observed days after planting (DAP) for heading (R1 stage) and blooming (R2 stage) had an RMSE of 4.3 days and MSEs and MSEns of $0.9 \%$ and $99.1 \%$, respectively (Figure 2B). The BIAS index was close to zero, dw was 0.95 and $r$ was 0.91 . These results indicate a good performance of the PhenoGlad model to simulate the cumulative leaf number and the reproductive developmental stages, including the harvest point, of gladiola in different locations of Rio Grande do Sul State.

Figure 3 shows a comparison of DAP until blooming (R2 stage), simulated with the PhenoGlad model using observed meteorological data and the baseline period. The RMSE was 2.5 days to harvest spikes for Mother's Day (Figure 3A). The MSEs and MSEns was $39.8 \%$ and $60.2 \%$, respectively. The BIAS index was close to zero, and $\mathrm{dw}$ and $\mathrm{r}$ presented values of 0.96 and 0.95 , respectively. The RMSE was 5.6 days (Figure 3B), the MSEs was $32.7 \%$, and the MSEns was $67.3 \%$ to harvest spikes for All Souls' Day. Similar to the comparison to Mother's Day, the BIAS index close to zero and, $d w$ and $r$ were 0.96 and 0.94 , respectively. This comparison indicates that climate of the baseline is similar to current climate in the State.

\section{Simulations of the optimum planting date}

The spatial distribution of anomalies of optimum planting date to harvest gladiola for All Souls' Day for each climate scenario is shown in Figure 4. For the RCP2.6 scenario (Figures 4A, 4D, 4G, 4J), optimum planting date anomalies varied from +5 to +10 days (later planting date compared to the baseline) for most Rio Grande do Sul State and, in some regions, the shift may reach +15 days later than today.
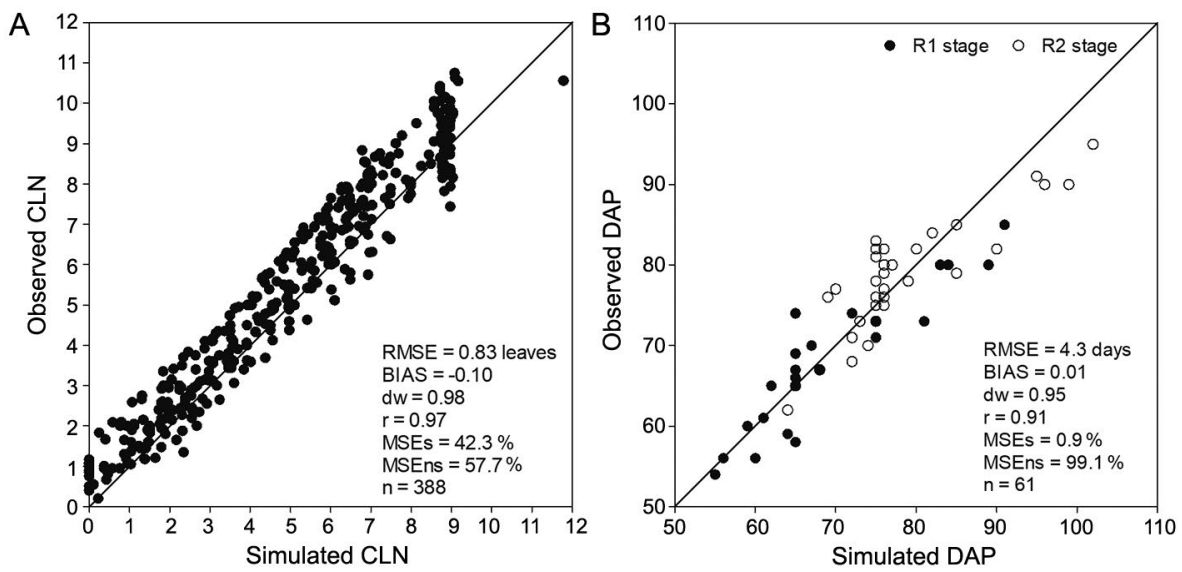

Figure 2 - The simulated versus observed cumulative leaf number (CLN) (A) and the simulated versus observed days after planting (DAP) until heading (R1) and blooming (R2) for gladiola in four locations in Rio Grande do Sul State, Brazil (Santa Maria, Dilermando de Aguiar, Cachoeira do Sul, and Santiago) (B). Data on all planting dates and cultivars are pooled. The solid line is 1:1 line. RMSE = root mean square error, BIAS = BIAS index, $d w=$ index of agreement, $r=$ correlation coefficient, MSEs = percentage of systematic means square error, MSEns = percentage of unsystematic mean square error, $\mathrm{n}=$ number of observations. 

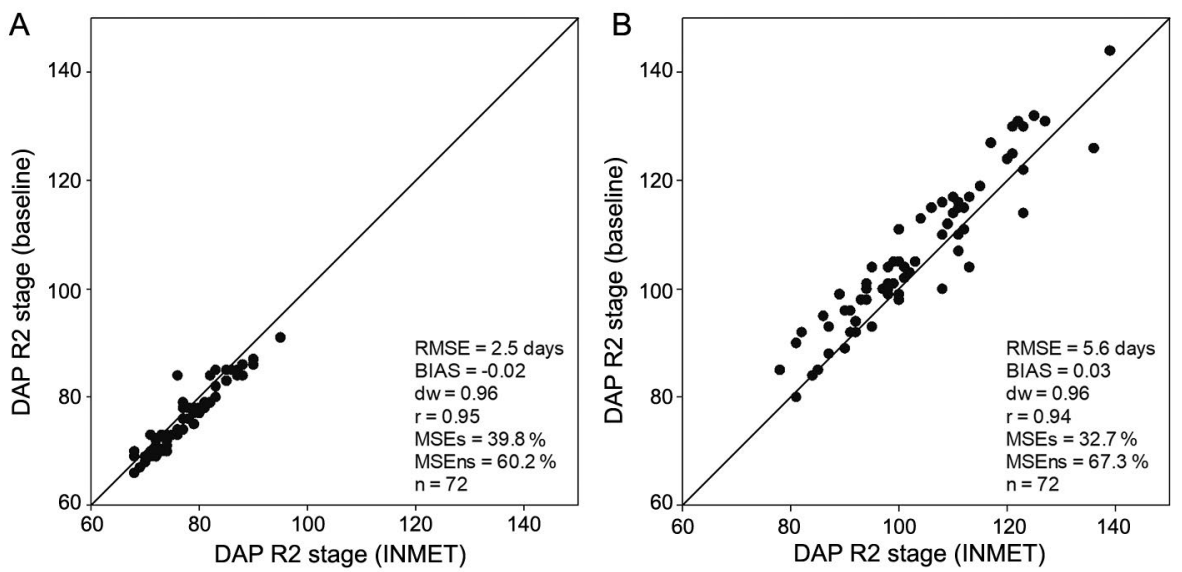

Figure 3 - Days after planting (DAP) until blooming (R2 stage) for planting aiming harvesting gladiola for (A) Mother's Day and for (B) All Souls' Day simulated with observed weather data from the Brazilian National Weather Service (INMET) and simulated with the baseline period (19762005) for 18 locations in the Rio Grande do Sul State. Data on all maturity groups of gladiola (Early, Intermediate I, Intermediate II and Late) are pooled. The solid line is 1:1 line. RMSE = root mean square error, BIAS = BIAS index, $d w=$ index of agreement, $r=$ correlation coefficient, MSEs = percentage of systematic means square error, MSEns = percentage of unsystematic mean square error, $n=$ number of observations.

In the RCP4.5 scenario, the greatest positive anomalies occurred in the coldest region in Rio Grande do Sul located in the northeastern part of the state, indicating greater effect of climate change in these regions (Figures 4B, 4E, 4H, 4K). The anomalies of planting date may reach +35 days for Intermediate II and Late MG (Figures $4 \mathrm{H}$ and $4 \mathrm{~K}$ ). In most Rio Grande do Sul State, anomalies range from +10 to +15 days for early $M G$, from +15 to +20 days for Intermediate I and Intermediate II MG, and from +20 to +25 days for Late MG. In the RCP8.5 scenario, most of the state presents positive anomalies from +20 to +25 days for Early, Intermediate I and II, and +25 to +30 in Late $\mathrm{MG}$ (Figures $4 \mathrm{C}, 4 \mathrm{~F}, 4 \mathrm{I}, 4 \mathrm{~L}$ ) and can reach +55 days for Late $M G$ in the northeastern region (Figure $4 \mathrm{~L}$ ). The trend is that planting date of Late MG needs to be delayed more than the Early MG. As the cycle length of these cultivars is higher, they are planted at the end of winter, when temperatures are lower than the optimum temperature. An increase in temperature during these colder days affects more the developmental of these cultivars thus delaying the planting date.

The spatial distribution of anomalies of optimum planting date to harvest gladiola for Mother's Day for each climatic scenario is shown in Figure 5. For the RCP2.6 scenario (Figures 5A, 5D, 5G, 5J), most Rio Grande do Sul State presents anomalies of +5 days and warmer regions, such as the northwestern region, present negative anomalies of up to - 5 days (earlier planting date compared to baseline) for all gladiola maturity groups. For scenarios RCP4.5 (Figures 5B, 5E, $5 \mathrm{H}, 5 \mathrm{~K}$ ) and RCP8.5 (Figures 5C, 5F, 5I, 5L), most Rio Grande do Sul State presents anomalies of +5 days as well as in scenario RCP2.6. However, in RCP8.5 scenario, anomalies may reach - 10 to - 15 days in the northwestern part of state and +10 to +15 days in northeastern region (Figure 5L). The temperature increase during the summer months affects more the optimum planting date of Late MG than Early MG cultivars, as Late MG are exposed to environmental conditions during more days.

\section{Plant injuries}

During the growing season to harvest for All Souls' Day, the crop was killed by frost in ten grid points of the baseline period in all gladiola MG (Early, Intermediate I, Intermediate II, and Late) in only one year (data not shown). For scenario RCP8.5, the crop was killed by heat in ten grid points in all gladiola MG in up to three years (data not shown). To harvest spikes for Mother's Day, no spike killed by heat or frost was simulated in the three climate scenarios and in the baseline.

In most Rio Grande do Sul State, the anomaly of percentage of years when severe burning of sepals occurred in the cultivation for All Souls' Day reached + $20 \%$ (20\% more years than the baseline) in scenarios RCP2.6 (Figures 6A, 6D, 6G, 6J) and RCP4.5 (Figures 6B, $6 \mathrm{E}, 6 \mathrm{H}, 6 \mathrm{~K})$. Some regions showed negative anomalies of - $10 \%$ (10\% less years than the baseline). For the Late MG in scenario RCP4.5 (Figure 6K), the western region of the state showed anomalies of $+50 \%$ of years with injuries caused by the heat. The anomalies reached +70 $\%$ in the west of Rio Grande do Sul for the Late MG in the scenario RCP 8.5 (Figure $6 \mathrm{~L}$ ) and the other gladiola MG reached $+60 \%$ (Figures 6C, 6F, 6I). The lowest anomalies were $+10 \%$ and occurred in the South and Southeast of the state.

In the growing season to harvest spikes for Mother's Day, no burning of sepals caused by heat occurred in the baseline period and in scenario RCP2.6. In RCP4.5 and RCP8.5 scenarios, most state showed anomalies of $+10 \%$ and some regions showed anomalies of $+20 \%$ (data not shown). 


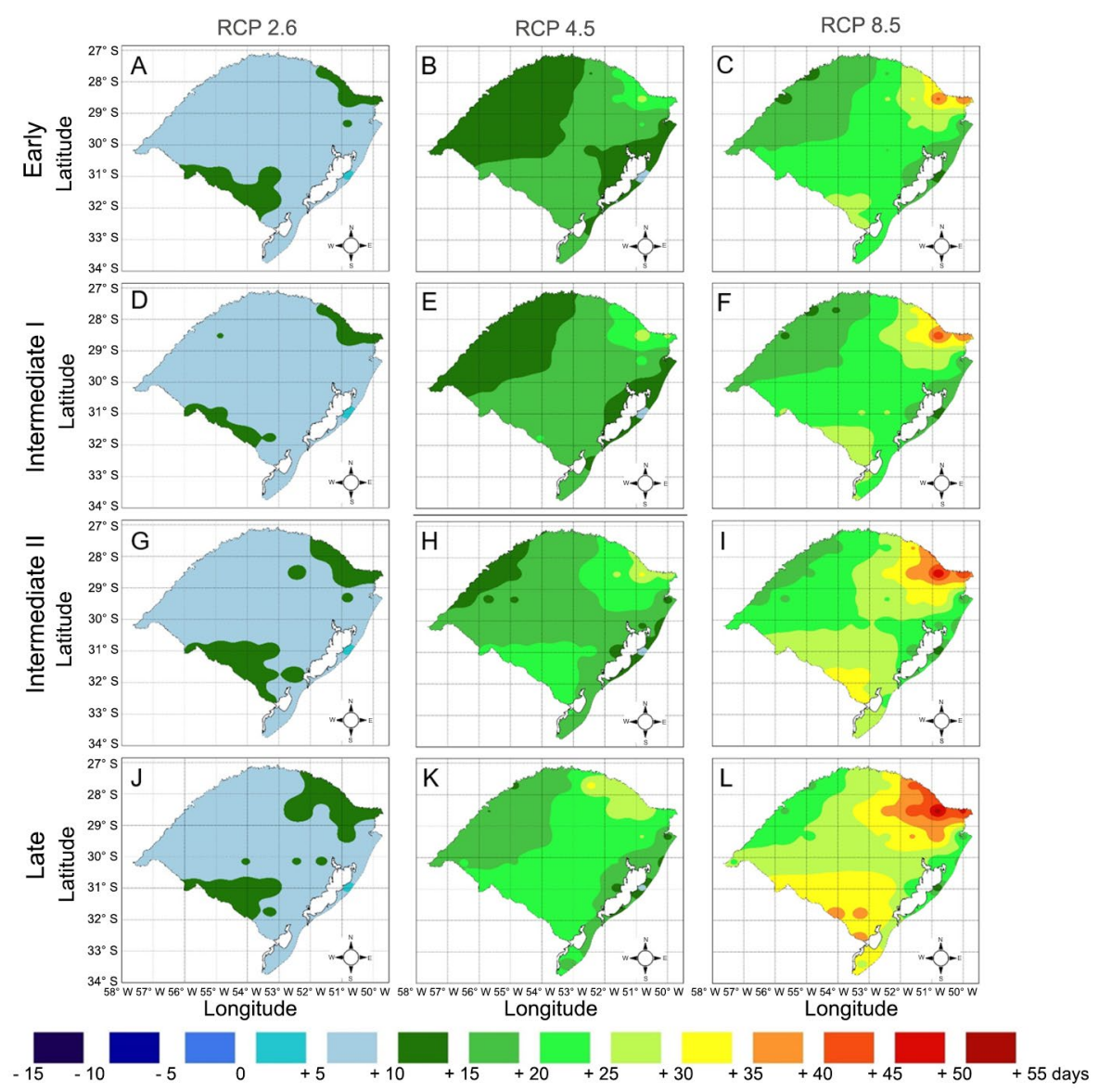

Figure 4 - Anomalies in optimum planting date for harvesting gladiola for All Souls' Day in the Rio Grande do Sul State, Brazil, as simulated with the PhenoGlad model for scenarios RCP2.6 (A, D, G and J), RCP4.5 (B, E, H and K) and RCP8.5 (C, F, I and L) for Early (A, B and C), Intermediate I (D, E and F), Intermediate II (G, H and I) and Late (J, K and L) maturity groups.

\section{Discussion}

\section{Simulations of optimum planting date}

A delay in the optimum planting date (positive anomalies) to harvest gladiola for All Souls' Day in future climate scenarios is attributed to an increase in minimum and maximum temperature in all regions of the state (Figures 7 and 8), which leads to an increase in developmental rate and a decrease in length of the developmental cycle (Adil et al., 2013; Schwab et al., 2015). Ornamental crops, such as Antirrhinum manus L. (Munir et al., 2004; Munir et al., 2015), Celosia argentea L. and Impatiens walleriana Hook. F. (Pramuk and Runkle, 2005), Brunonia australis and Calandrinia sp. (Cave et al., 2013), Salvia splendens and Tagetes patula (Moccaldi and Runkle, 2007), Chysanthemum morifolium (Larsen and Persson, 1999), 18 species of annual bedding plants (Blanchard and Runkle, 2011), and Petunia $\times$ hybrida (Blanchard et al., 2011) present a similar response to rising temperature; however, their response was not evaluated in the scenarios of climate change.
The northeastern region (the coolest region) of Rio Grande do Sul State had the greatest positive anomalies in the planting date, because in future climate scenarios, temperatures are closer to the optimum temperature for gladiola $\left(27^{\circ} \mathrm{C}\right.$ for the vegetative phase and $25^{\circ} \mathrm{C}$ for the reproductive phase). When average daily air temperature is below or above the optimum temperature for the crop, the development rate is penalized by the nonlinear temperature response function (Uhlmann et al., 2017), increasing the cycle duration. In RCP8.5 scenario, minimum and maximum air temperatures are greater (Figures 7 and 8) and exceeded the optimum temperature for the crop, leading to the highest positive anomalies (+ 55 days) in the optimum planting date in this region (Figure $4 \mathrm{~L}$ ). This implies that, in the future, farmers should plant gladiola corms almost two months later than they currently do. In addition to the effect on developmental rate, several studies have reported a decrease in quality of ornamental crops with increases in temperature, because a faster crop development leads to a reduced number of flower buds, smaller flower size and less plant biomass (Pramuk and Runkle, 2005; 


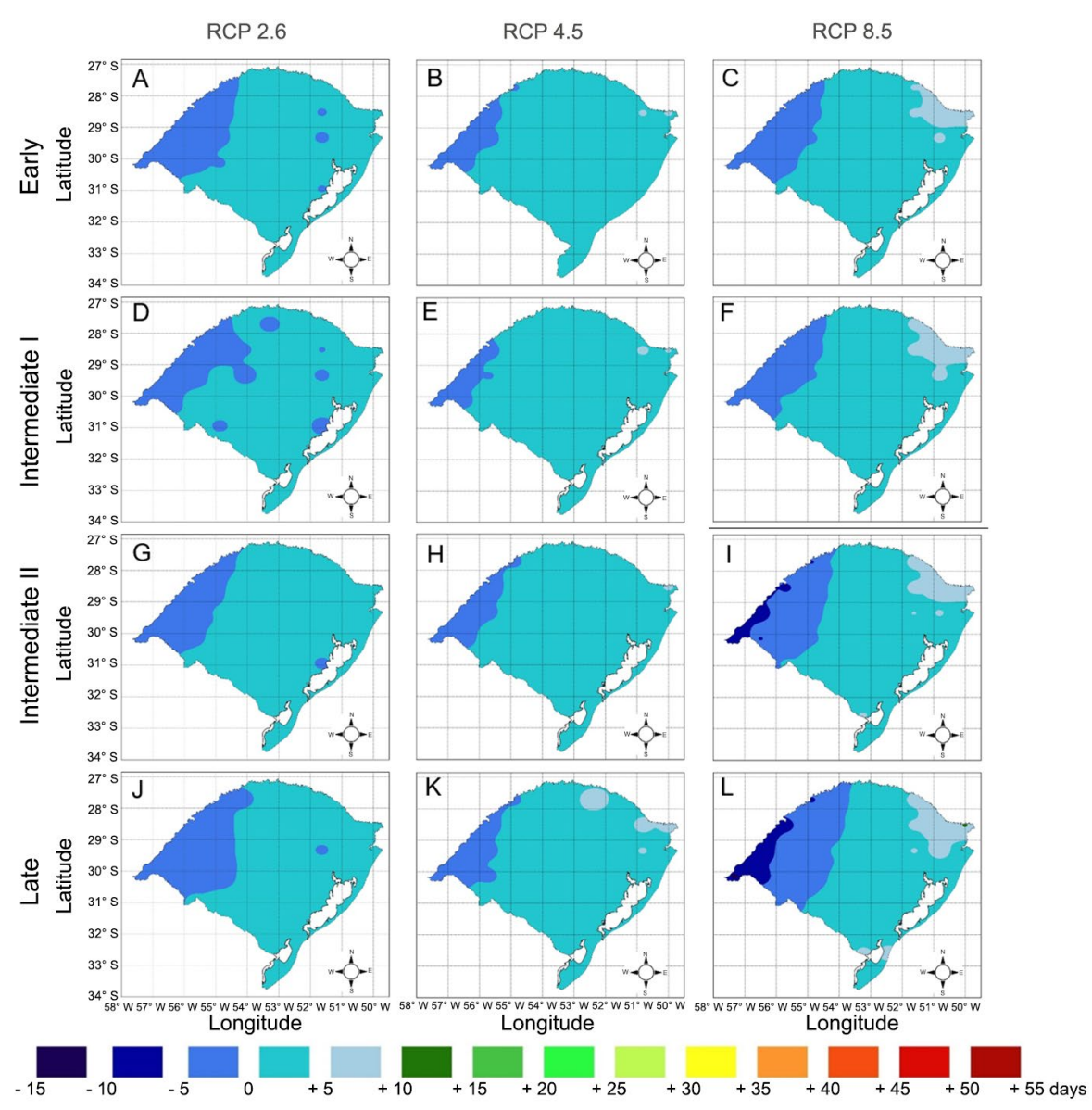

Figure 5 - Anomalies in optimum planting date for harvesting gladiola for Mother's Day in the Rio Grande do Sul State, Brazil, as simulated with the PhenoGlad model for scenarios RCP2.6 (A, D, G and J), RCP4.5 (B, E, H and K) and RCP8.5 (C, F, I and L) for Early (A, B and C), Intermediate I (D, E and F), Intermediate II (G, H and I) and Late (, $\mathrm{K}$ and $\mathrm{L})$ maturity groups.

Moccaldi and Runkle, 2007; Blanchard et al., 2011, Vaid et al., 2014). In crops, such as soybean (Rio et al., 2015), potato (Wang et al., 2015b) and wheat (Wang et al., 2015a), a shortening in developmental cycle leads to a shorter leaf development phase, leading to a smaller amount of radiation intercepted and consequently decreasing crop yield. An alternative for the negative effect of the shortening of the gladiola cycle on growth of the plants and on the quality of the flower stems may be choosing Late MG cultivars, which have a longer developmental cycle.

In the future climate scenarios used in this study, the minimum air temperature is quite high, mainly in the western region of the state to harvest spikes for Mother's Day (Figure $7 \mathrm{H}$ ) when air temperature exceeded the optimal temperature for gladiola mainly in the scenario RCP8.5. When temperature exceeds the optimum level, the developmental rate decreases (Blanchard and Runkle, 2011; Cave et al., 2013; Uhlmann et al., 2017), resulting in a longer developmental cycle (Schwab et al., 2015). In the western region of the state, negative anomalies of optimum planting date (earlier planting date) to harvest for Mother's Day (Figures 5C, 5F, 5I, $5 \mathrm{~L})$ can be explained by a greater frequency in above optimum temperatures for development, mainly in RCP8.5 scenario (Figures $7 \mathrm{H}$ and $8 \mathrm{H}$ ).

\section{Plant injuries}

Crop killed by frost for All Souls' Day harvest occurred only in the baseline in the northern region of the state, because the initial development of crop happens at the end of winter, when minimum temperatures are lower (Figure 7A). The increase in minimum temperature observed in the climate scenarios resulted in no crop killed by frost in the growing season for All Souls' Day (Figures 7A-E). In the growing season to harvest gladiola for Mother's Day, minimum temperatures are not so low because planting is performed at the end of summer and most development occurs during fall (Figures 7F-J). Therefore, for this growing season, no crop was killed by frost. Crop was killed by heat for All Souls' Day harvest only in RCP8.5 period mainly in the northern region of the state, because the maximum temperature exceeded $48{ }^{\circ} \mathrm{C}$ (Figure 8A). 


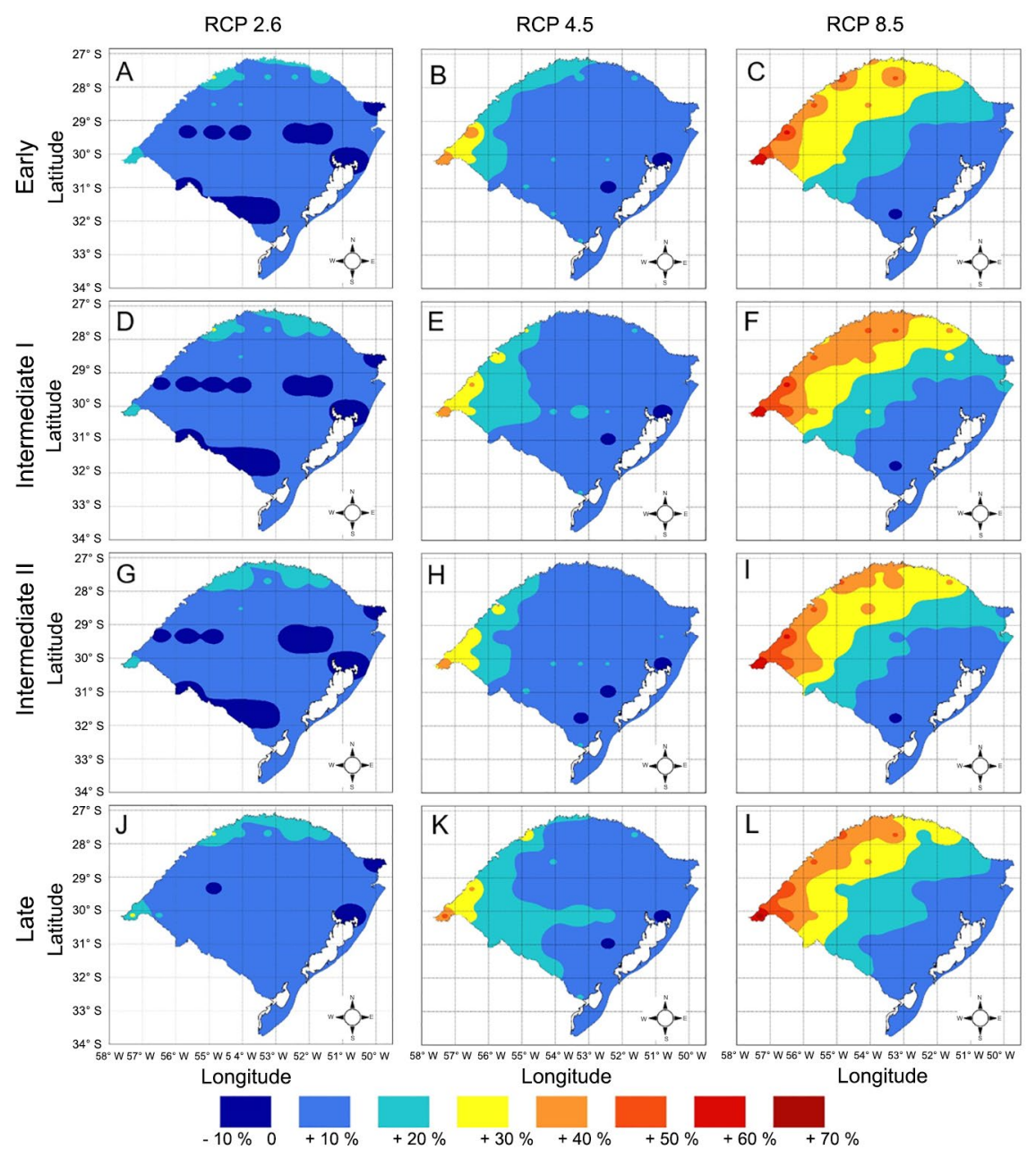

Figure 6 - Anomaly of the percentage of years that occurred heat injury in the growing season for harvesting gladiola for All Souls' Day in the Rio Grande do Sul State, Brazil, as simulated with the PhenoGlad model for scenarios RCP2.6 (A, D, G and J), RCP4.5 (B, E, H and K) and RCP8.5 (C, F, I and L) for Early (A, B and C), Intermediate I (D, E and F), Intermediate II (G, H and I) and Late (, $\mathrm{K}$ and $\mathrm{L}$ ) maturity groups.

The risk of injuries on florets caused by heat was more intense in the growing season to harvest for All Souls' Day than for Mother's Day, mainly in RCP8.5 scenario in the warmest regions (north and west) (Figures $6 \mathrm{C}, 6 \mathrm{~F}, 6 \mathrm{I}, 6 \mathrm{~L})$. This happened because of the high maximum temperature in these regions (Figures $8 \mathrm{~A}$ and $8 \mathrm{C}$ ) at the end of the growing season (when plants are in the reproductive phase), whereas for Mother's Day, injuries are less frequent (Figures $8 \mathrm{~F}$ to $8 \mathrm{~J}$ ). The regions South (Figure 8B), Center (Figure8D) and East (Figure $8 \mathrm{E})$ present mild maximum temperatures, therefore, the risk of injuries is lower. The RCP8.5 scenario was also the most damaging to winter wheat in Australia, because of the lower frequency of cold days that affects vernalization (Wang et al., 2015a).

The production of gladiola to sell on All Souls' Day is more affected by climate change than on Mother's Day. Although there is a reduction in the occurrence of crop killed by frost, in scenario RCP8.5, there was occurrence of crop killed by heat (data not shown). The southern and eastern regions were more favored in scenario RCP8.5 due to less occurrence of injuries caused by heat (Figure 6). These injuries reduce the quality of floral stems thus decreasing their market value.

\section{Practical implications of this study}

The results of this study have practical applications for strategies in southern Brazil under future climate scenarios. One application is a shift of current planting date of gladiola to meet the demand in consumption peaks in future climate scenarios. In order to sell gladiola on All Souls' Day, and considering the more optimist scenario RCP2.6, most farmers of the state need to carry out the planting between 5 and 10 days later than they currently do. In RCP4.5 

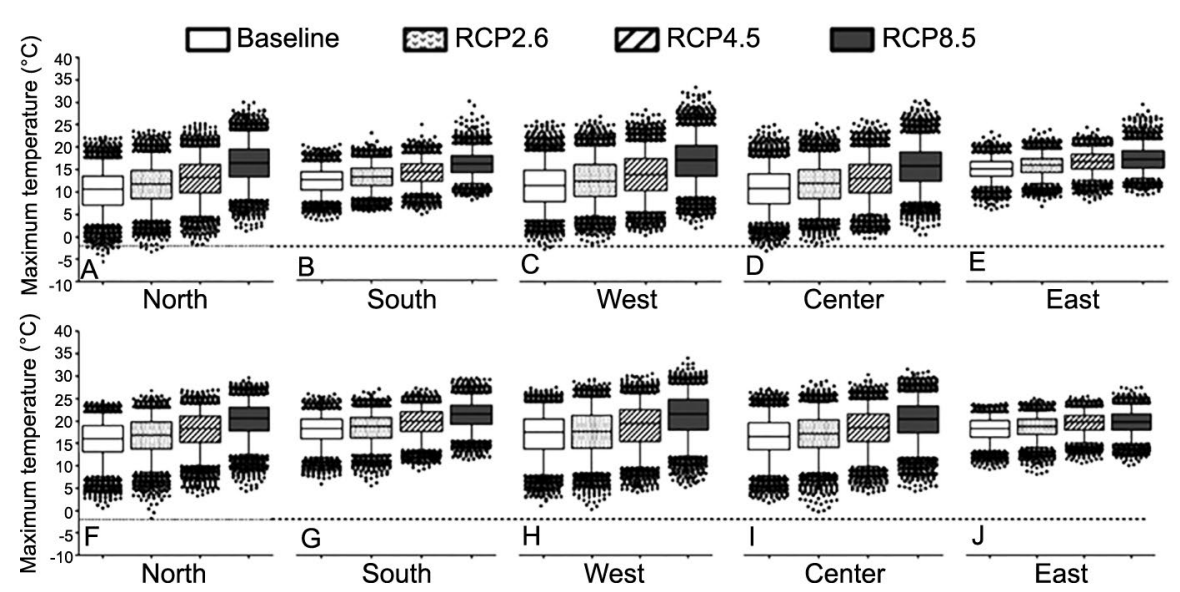

Figure 7 - Minimum temperature in CMIP5 climate scenarios during the growing season for harvesting gladiola for All Souls' Day (panels: A, B, C, D, E) and for Mother's Day (panels: F, G, H, I, J) for five grid points located in different regions of the Rio Grande do Sul State, Brazil: North

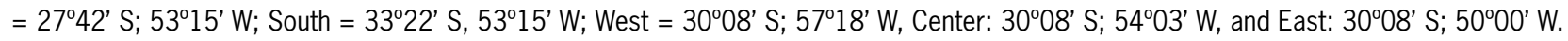
The dotted line indicates the threshold temperature of $-2{ }^{\circ} \mathrm{C}$ in which crop is killed by frost.

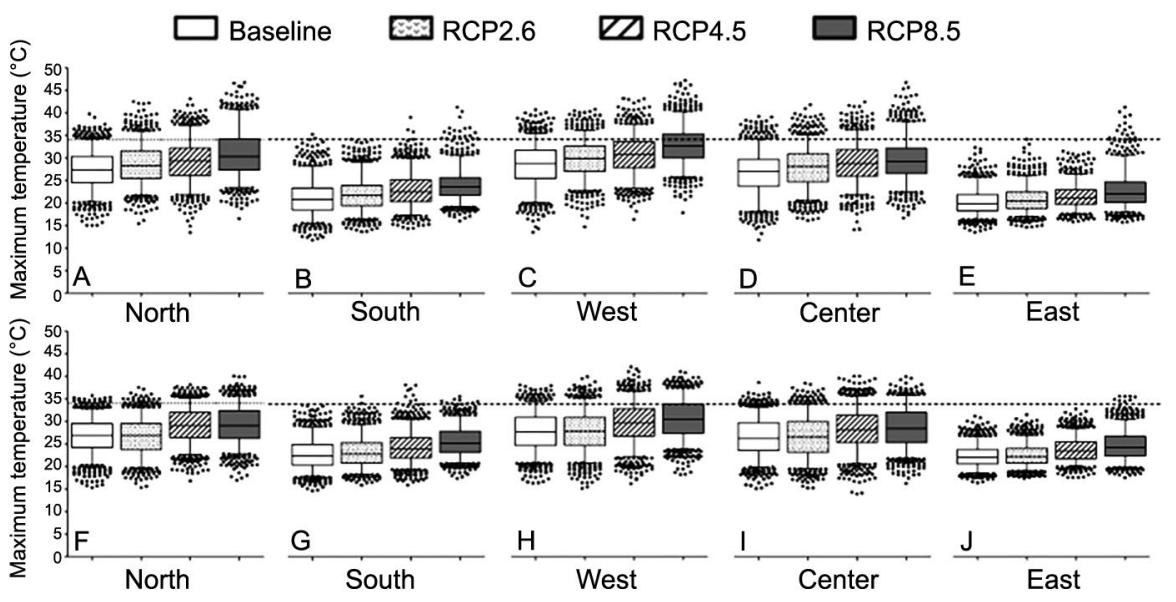

Figure 8 - Maximum temperature in the CMIP5 climate scenarios during the reproductive phase for harvesting gladiola for All Souls' Day (panels: A, B, C, D, E) and for Mother's Day (panels: F, G, H, I, J) for five grid points located in different regions of the Rio Grande do Sul State, Brazil:

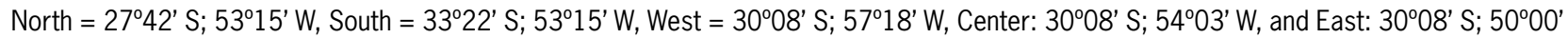
$\mathrm{W}$. The dotted line indicates the threshold temperature of $34{ }^{\circ} \mathrm{C}$ that causes severe burning of sepals.

scenario, in most state, planting needs to be carried out up to 25 days later (Late MG). In RCP8.5 scenario, planting should be carried out about 55 days later in the northeastern region of the state, which has the highest altitude and the coldest temperatures in current climate. If farmers do not adjust the planting date, gladiola flower stems become ready for harvest way before the date of sale.

Another application of this study is that future temperatures are more harmful to florets, decreasing spikes quality, mainly in the growing season for harvest for All Souls' Day. Therefore, these results highlight the importance of research about the effect of shading screens on reducing damage from high temperatures on gladiola flower stems. The use of screens reduced the occurrence of sunburned peppers during the summer months in southern Spain (López-Marin et al., 2011). Another strategy may come from breeding programs, which should focus on developing gladiola cultivars more tolerant to high temperatures.

The results of this study have practical applications for strategies in southern Brazil, mainly to enable the production of gladiola by small farmers and ensure access to flowers produced locally. Gladiola producers from major producing countries, such as Bulgaria, the United States, and India, have studied the impact of climate change on agricultural crops, but not on gladiola (Alexandrov and Hoogenbom, 2000; Fei et al., 2017; Srivastava et al., 2010). Therefore, effects of climate change on gladiola demonstrated in this study and the strategies to mitigate these effects are also relevant information to these countries. 


\section{Conclusions}

Flowering time of gladiola is strongly driven by temperature. Therefore, a shift in planting date in the Rio Grande do Sul State to meet demands of marketable days may occur in scenarios of future climate change. Our simulations suggest a delay in planting date of gladiola to harvest for All Souls' Day in future climate scenarios of up to 55 days in RCP8.5 scenario for the coldest region of the state. To harvest for Mother's Day, negative anomalies (earliest planting date) occurred in the warmest regions because temperatures exceeded the optimum temperature, decreasing the developmental rate of gladiola. Gladiola flower quality may also be affected by climate change due to heat stress and injury. Mitigation strategies for farmers to deal with climate change and keep their gladiola production in southern Brazil include adapting the optimum planting date.

\section{Acknowledgements}

The authors thank extensionists from Empresa de Assistência Técnica e Extensão Rural do Rio Grande do Sul (EMATER, RS - Ascar): Alfredo Schons, Luana Fernandes Tironi, Silvio Augusto Wilhelm and Otávio Mendonça Poleto for technical support during data collection at the farms in the municipalities of Dilermando de Aguiar, Cachoeira do Sul, and Santiago. This study was supported by Conselho Nacional de Desenvolvimento Científico e Tecnológico (CNPq) (Proc. No. 302858/2015-6) and Coordenação de Aperfeiçoamento de Pessoal de Nivel Superior (CAPES).

\section{Authors' Contributions}

Conceptualization: Becker, C.C.; Streck, N.A.; Uhlmann, L.O.; Cera, J.C. Data acquisition: Becker, C.C.; Silveira, W.B.; Ferraz, E.T.; Silva, L.F. Data analysis: Becker, C.C.; Balest, D.S.; Silveira, W.B.; Cera, J.C. Design of methodology: Becker, C.C.; Streck, N.A.; Uhlmann, L.O.; Ferraz, E.T.; Cera, J.C. Writing and editing: Becker, C.C.; Streck, N.A.; Uhlmann, L.O.; Cera, J.C.; Ferraz, E.T.; Silveira, W.B.; Balest, D.S.; Silva, L.F.

\section{References}

Adil, M.; Ahmad, W.; Ahmad, K.S.; Shafi, J.; Shehzad, M.A.; Sarwar, M.A.; Salman, M.; Ghani, M.I.; Iqabal, M. 2013. Effect of different planting dates on growth and development of Gladiolus grandiflorus under the ecological conditions of Faisalabad, Pakistan. Universal Journal of Agricultural Research 1: 110-117.

Alexandrov, V.A.; Hoogenboom, G. 2000. The impact of climate variability and change on crop yield in Bulgaria. Agricultural and Forest Meteorology 104: 315-327.

Alvares, C.A.; Stape, J.L.; Sentelhas, P.C.; Gonçalves, J.L.M.; Sparovek, G. 2013. Köppen's climate classification map for Brazil. Meteorologische Zeitschrift 22: 711-728.
Becker, C.C.; Streck, N.A.; Uhlmann, L.O.; Silveira, W.B. 2020. Scheduling optimum planting window for gladiola based on El Nino Southern Oscillation. Scientia Agricola 77: e20180336.

Bhattarai, M.D.; Secchi, S.; Schoof, J. 2017. Projecting corn and soybeans yields under climate change in a Corn Belt watershed. Agricultural Systems 152: 90-99.

Blanchard, M.G.; Runkle, E.S. 2011. Quantifying the thermal flowering rates of eighteen species of annual bedding plants. Scientia Horticulturae 128: 30-37.

Blanchard, M.G.; Runkle, E.S.; Fisher, P.S. 2011. Modeling plant morphology and development of petunia in response to temperature and photosynthetic daily light integral. Scientia Horticulturae 129: 313-320.

Cave, R.L.; Hammer, G.L.; McLean, G.; Birch, C.J.; Erwin, J.E.; Johnston, M.E. 2013. Moddeling temperature, photoperiod and vernalisation responses of Brunonia australis (Goodeniaceae) and Calandrinia sp. (Portulacaceae) to predict flowering time. Annals of Botany 111: 629-639.

Cera, J.C.; Streck, N.A.; Fensterseifer, C.A.J.; Ferraz, S.E.T.; Bexaira, K.P.; Silveira, W.B.; Cardoso, A.P. 2017. Soybean yield in future climate scenarios for the state of Rio Grande do Sul, Brazil. Pesquisa Agropecuária Brasileira 52: 380-392.

Fei, C.J.; McCarl, B.A.; Thayer, A.W. 2017. Estimating the impacts of climate change and potential adaptation strategies on cereal grains in the United States. Frontiers in Ecology and Evolution 5: article 62.

Fisher, P.R.; Lieth, J.H. 2000. Variability in flower development of Easter lily (Lilium longiflorum Thunb.): model and decisionsupport system. Computers and Electronics in Agriculture 26: 53-64.

Hur, J.; Ahn, J.B. 2015. The change of first-flowering date over South Korea projected from downscaled IPCC AR5 simulation: peach and pear. International Journal of Climatology 35: 19261937.

IPCC. 2013. Climate Change 2013: The Physical Science Basis. Contribution of Working Group I to the Fifth Assessment Report of the Intergovernmental Panel on Climate Change. Cambridge University Press, Cambridge, UK.

Jones, C.D.; Hughes, J.K.; Bellouin, N.; Hardiman, S.C.; Jones, G.S.; Knight, J.; Liddicoat, S.; O'Connor, F.M.; Andres, R.J.; Bell, C.; Boo, K.-O.; Bozzo, A.; Butchart, N.; Cadule, P.; Corbin, K.D.; Doutriaux-Boucher, M.; Friedlingstein, P.; Gornall, J.; Gray, L.; Halloran, P.R.; Hurtt, J.; Ingram, W.J.; Lamarque, J.F.; Law, R.M.; Meinshausen, M.; Osprey, S.; Palin, E.J.; Chini, L.P.; Raddatz, T.; Sanderson, M.G.; Sellar, A.A.; Schurer, A.; Valdes, P.; Wood, N.; Woodward, S.; Yoshioka, M.; Zerroukat, M. 2011. The HadGEM2-ES implementation of CMIP5 centennial simulations. Geoscientific Model Development 4: 543-570.

Larsen, R.U.; Persson, L. 1999. Modelling flower development in greenhouse chrysanthemum cultivars in relation to temperature and response group. Scientia Horticulturae 80: 73-89.

López-Marin, J.; González, A.; Gálvez, A. 2011. Effect of shade on quality of greenhouse peppers. Acta Horticulturae 893: 895900.

Marengo, J.A.; Camargo, C.C. 2008. Surface air temperature trends in southern Brazil for 1960-2002. International Journal of Climatology 28: 893-904. 
Moccaldi, L.A.; Runkle, E.S. 2007. Modeling the effects of temperature and photosynthetic daily integral on growth and flowering of Salvia splendens and Tagetes patula. Journal of the American Society for Horticultural Science 132: 283-288.

Munir, M.; Hadley, P.; Carew, J.; Adams, S.; Pearson, S.; Sudhakar, B. 2015. Effect of constant temperatures and natural daylength on flowering time and leaf number of Antirrhinum using the photo-thermal model. Pakistan Journal of Botany 47: 17171720 .

Munir, M.; Jamil, M.; Baloch, J.-U.-D.; Khattak, K.R. 2004. Growth and flowering of Antirrhinum majus L. under varying temperatures. International Journal of Agriculture \& Biology 6: 173-178.

Pramuk, L.A.; Runkle, E.S. 2005. Modeling growth and development of celosia and impatiens in response to temperature and photosynthetic daily light integral. Journal of the American Society for Horticultural Science 130: 813-818.

Ramirez-Villegas, J.; Thornton, P.K. 2015. Climate change impacts on African crop production. CGIAR Research Program on Climate Change, Agriculture and Food Security. Copenhagen, Denmark. (CCAFS Working Paper, 119). Available at: https:// ccafs.cgiar.org/publications/climate-change-impacts-africancrop-production\#.XUQz8uhKiM8 [Accessed Aug 01, 2019]

Rio, A.; Sentelhas, P.C.; Farias, J.R.B.; Sibaldelli, R.N.R.; Ferreira, R.C. 2015. Alternative sowing dates as a mitigation measure to reduce climate change impacts on soybean yields in southern Brazil. International Journal of Climatology 36: 3664-3672.

Schwab, N.T.; Streck, N.A.; Becker, C.C.; Langner, J.A.; Uhlmann, L.O.; Ribeiro, B.S.M.R. 2015. A phenological scale for the development of Gladiolus. Annals of Applied Biology 166: 496507.

Srivastava, A.; Naresh Kumar, S.; Aggarwal, P. K. 2010. Assessment on vulnerability of sorghum to climate change in India. Agriculture, Ecosystems \& Environment 138: 160-169.
Snipen, L.G.; Moe, R.; Soreng, J. 1999. Influence of potential growth factors in predicting time to flowering in poinsettia (Euphorbia pulcherrima). Scientia Horticulturae 81: 345-359.

Thakur, T.; Dhatt, K.K.; Ahmed, S. 2015. Effect of planting time on growth and flowering of Gladiolus. International Journal of Current Research and Academic Review 3: 145-152.

Uhlmann, L.O.; Streck, N.A.; Becker, C.C.; Schwab, N.T.; Benedetti, R.P.; Charão, A.S.; Ribeiro, B.S.M.R.; Silveira, W.B.; Backes, F.A.A.L.; Alberto, C.M.; Muttoni, M.; Paula, G.M.; Tomiozzo, R.; Bosco, L.C.; Becker, D. 2017. PhenoGlad: A model for simulating development in Gladiolus. European Journal of Agronomy 82: 33-49.

Wallach, D. 2006. Evaluating crop models. p. 11-50. In: Wallach, D.; Makowski, D.; Jones, J.W., eds. Working with dynamic crop models: evaluation, analysis, parameterization, and applications. Elsevier, Amsterdam, The Netherlands.

Wang, B.; Liu, D.L.; Asseng, S.; Macadam, I.; Yu, Q. 2015a. Impact of climate change on wheat flowering time in eastern Australia. Agricultural and Forest Meteorology 209-210: 11-21.

Wang, C.-L.; Shen, S.-H.; Zhang, S.-Y.; Li, Q.-Z.; Yao, Y.B. 2015b. Adaptation of potato production to climate change by optimizing sowing date in the Loess Plateau of central Gansu, China. Journal of Integrative Agriculture 14: 398-409.

Wang, E.; Engel, T. 1998. Simulation of phenological development of wheat crops. Agricultural Systems 58: 1-24.

Willmott, C.J. 1981. On the validation of models. Physical Geography 2: 184-194.

Vaid, T.M.; Runkle, E.S.; Frantz, J.M. 2014. Mean daily temperature regulates plant quality attributes of annual ornamental plants. HortScience 49: 574-580. 